\title{
Visibilidade comunicativa na Internet: uma análise da fan page de Marcelo Freixo
}

\author{
Communicative visibility on the Internet: an analysis of Marcelo Freixo's fan \\ page
}

\section{Visibilidad comunicativa en Internet: un análisis de la página de fans de Marcelo Freixo}

\author{
Wesley Pereira Grijó ${ }^{1}$ \\ Ícaro Gracian da Silva Vieira ${ }^{2}$
}

\begin{abstract}
Resumo
A partir da interface entre Comunicação e Política, o artigo aborda como a perspectiva da visibilidade é materializada na fan page do político Marcelo Freixo, levando em consideração os temas e a periodicidade com que são trabalhadas cada postagem. Para essa finalidade, o estudo é de abordagem quantitativa e qualitativa e utiliza para coleta de dados as pesquisas bibliográfica e documental no ambiente da internet. No que concerne aos resultados, o agente político e sua assessoria realizam, em média, quatro publicações diárias na página oficial, agrupadas em cinco temáticas: promoção de ideias e projetos; ataques e respostas a adversários; divulgação de eventos; mobilização, engajamento e apoio; mensagens alheias à política. Nelas, verifica-se a tentativa de engajar e mobilizar os eleitores para que abracem as causas e ideias do político, aproveitando a projeção da visibilidade conquistada nas eleições também fora do período eleitoral.
\end{abstract}

\begin{tabular}{|c|c|}
\hline & Acesse este artigo online \\
\hline \multirow{2}{*}{ 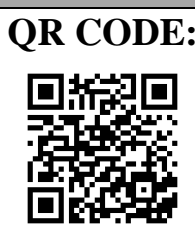 } & $\begin{array}{l}\text { Website: } \\
\text { http://www.revistas.ufg.br/index.php/ci }\end{array}$ \\
\hline & $\begin{array}{l}\text { DOI: } \\
\text { http://dx.doi.org/10.5216/ci.v20i3.42523 }\end{array}$ \\
\hline
\end{tabular}

Palavras-chave: Redes sociais online. Visibilidade. Comunicação política.

Abstract
From the interface between communication and political, this article discusses how the perspective of visibility is based upon the fan page politician Marcelo Freixo, taking into account the themes and the frequency with which they are worked each post. For this purpose, the study is quantitative and qualitative approach and used for data collection of bibliographic and documentary research on the Internet environment. Regarding the results, the political agent and his staff carry out an average of four daily publications in the official page, grouped into five themes: promoting ideas and projects; attacks and responses to opponents; dissemination events; mobilization, engagement and support; alien messages to politics. In them, there is an attempt to engage and mobilize voters to embrace the causes and ideas of politics, taking advantage of the projection and maintenance of visibility won the elections also outside the election period.

Keywords: Online social networks. Visibility. Political communication.

\section{Resumen}

\footnotetext{
${ }^{1}$ Professor adjunto da Universidade Federal de Santa Maria. Doutor em Comunicação e Informação pela Universidade Federal do Rio Grande do Sul. E-mail: wgrijo@yahoo.com.br.

${ }^{2}$ Graduando do curso de Relações Públicas com Ênfase em Produção Cultural da Universidade Federal do Pampa. E-mail: icarogracian@hotmail.com.
}

Comun. \& Inf., Goiânia, GO, v. 20, n. 3, p. 64-83, out./dez. 2017 
Desde la interfaz entre la comunicación y la política, se discute cómo la perspectiva de la visibilidad se basa en la página oficial del político Marcelo Freixo, teniendo en cuenta los temas y la frecuencia con la que se elaboran cada puesto. Para este propósito, el estudio tiene enfoque cuantitativo y cualitativo y se utilizó para la recolección de datos de la investigación bibliográfica y documental sobre el entorno de Internet. En cuanto a los resultados, el agente político y su personal llevar a cabo un promedio de cuatro publicaciones diarias en la página oficial, agrupadas en cinco temas: la promoción de ideas y proyectos; ataques y respuestas a los oponentes; eventos de difusión; la movilización, participación y apoyo; mensajes extrañas al compromiso político. En ellos, hay un intento de comprometer y movilizar a los votantes para abrazar las causas y las ideas de la política, aprovechando la proyección y el mantenimiento de la visibilidad ganado las elecciones también fuera del periodo electoral.

Palabras clave: Redes sociales en línea. Visibilidad. Comunicación política.

\section{INTRODUÇÃO}

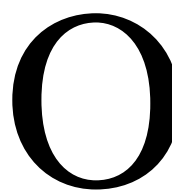

presente trabalho pretende analisar a construção da visibilidade por parte do agente político Marcelo Freixo ${ }^{3}$, por meio de sua página oficial homônima na rede social Facebook ${ }^{4}$. Do começo de sua luta política até hoje, passando pelo início da militância no Partido dos Trabalhadores (PT) até os três mandatos de deputado estadual pelo Partido Socialismo e Liberdade (PSOL), Freixo tem sido um político reconhecido pela defesa dos Direitos Humanos e da Cidadania, além de ser destaque na luta contra as milícias presentes no Rio de Janeiro.

Nos últimos tempos, tem sido conhecido também por sua presença nas redes sociais, das quais faz uso para estimular o financiamento colaborativo de suas campanhas eleitorais, mas, muito além disso, é o lugar onde ele - e sua assessoria - constantemente informa e dialoga com seus seguidores sobre sua atuação como político, seus projetos, promove discussões, entre outras iniciativas.

Ao realizarmos a pesquisa bibliográfica em estudos recentes que também produziram conhecimento sobre o comportamento de políticos nas redes sociais online, como Facebook e Twitter, verificamos que o presente artigo tem como diferencial a temporalidade da coleta de dados, pois não foi realizada em um momento de pleito eleitoral. Assim, nossa abordagem da visibilidade almeja saber também quais são as estratégias de comunicação no Facebook que o referido político utiliza para projetar a sua imagem e suas ideias fora do período eleitoral. Pelos estudos anteriores, cuja temporalidade se deu em período eleitoral, verificamos que a visibilidade quando conquistada eficazmente pode se transformar no sucesso do agente político em futuras eleições (MARQUES; SILVA; MATOS, 2011; GONÇALVES;

\footnotetext{
${ }^{3}$ Professor de história, militante dos direitos humanos e deputado estadual pelo PSOL-RJ.

${ }^{4}$ Disponível em: https://www.facebook.com/MarceloFreixoPsol/?fref=ts. Acesso em: 23 jun. 2016.
}

Comun. \& Inf., Goiânia, GO, v. 20, n. 3, p. 64-83, out./dez. 2017 
FERREIRA，2013; CASTRO; FERREIRA，2014; ITUASSU; CAPONE; PARENTE; PECORARO, 2014).

Empiricamente, observamos a página oficial mencionada em rede social na internet, verificando a quantidade de postagens, a periodicidade e os tipos de conteúdo, como forma de compreender como o agente político e sua assessoria de comunicação fazem uso das mídias sociais para projetar sua visibilidade. Assim, partimos de alguns questionamentos norteadores de nossa discussão: quais tipos de postagens mais repercutem? Quais atraem mais interação com os internautas (curtidas, comentários, compartilhamentos)? Como tais postagens promovem a visibilidade do político Marcelo Freixo?

Cabe frisar que a pertinência da escolha de Freixo para este estudo deve-se à sua participação assídua nas redes sociais online e também por ter sido eleito, em 2014, o deputado estadual mais votado do Brasil, com mais de 350 mil votos (RÁDIO AGÊNCIA NACIONAL, 2014). Dessa forma, hipoteticamente, partimos do pressuposto de que a maneira como ele se comunica com seus seguidores/eleitores no Facebook é muito eficaz para a promoção de sua imagem.

Nesse sentido, traçamos a estratégia metodológica deste estudo alicerçada em uma abordagem quantitativa e qualitativa, com a coleta de dados direcionada pelas pesquisas bibliográfica, documental e exploratória. Os dados presentes na fan page do deputado foram coletados entre os dias 28 de novembro e 04 de dezembro de 2015. Posteriormente, a análise das informações foi inspirada em procedimentos da Análise de Conteúdo. No que concerne às perspectivas teóricas, trabalhamos ao longo deste artigo quatro conceitos que consideramos essenciais para a contextualização do objeto empírico pesquisado:

1) Comunicação Política: a partir da contribuição de autores como Gomes (2009) e Trein (2013), com o intuito de demonstrar a que se refere esse tipo de comunicação e como ela é trabalhada pelo agente político em sua página oficial no Facebook;

2) Marketing Político: a partir dos estudos de Queiroz (2006) e Dantas (2010), cuja síntese indica que, na política, a ideia de marketing (de venda e compra de produto) também existe e que o agente político observado, ao compartilhar conteúdo com suas ideias, projetos e ideologias no Facebook, está "se vendendo" como um tipo de político que seus seguidores podem ou não “comprar";

3) Assessoria de Comunicação: os trabalhos de Torquato (2002), Ribeiro (2012) e Ferrari (2007) apontam que em um ambiente midiatizado, como o atual, o agente político precisa de uma assessoria especializada para trabalhar sua imagem diante da sociedade, nos 
diversos dispositivos digitais disponíveis para a Comunicação Política, pois, caso contrário, cairá em ostracismo;

4) Visibilidade: a perspectiva de Thompson (2008) concebe a ideia de que os meios de comunicação elaboram uma "nova visibilidade" mediada, evidenciando as ações e os acontecimentos cada vez mais difíceis de serem controlados na atual conjuntura da comunicação digital.

\section{VISIBILIDADE COMUNICATIVA NAS REDES SOCIAIS ONLINE}

$\mathrm{Na}$ observação das redes sociais online ${ }^{5}$ do político Marcelo Freixo, deparamo-nos com um exímio trabalho de assessoria de imprensa atrelada à prática da Comunicação Política como forma de promover a visibilidade do assessorado. No âmbito da Comunicação Política e do Marketing Político, a assessoria necessita exercer bem sua função para legitimar e projetar a imagem pública do político.

No cotidiano das práticas dos agentes políticos, o problema normalmente encontrado é que muitos donos de mandatos não tomam conhecimento do poder de estratégia e inteligência que uma assessoria possui e acabam por alocar pessoas, que não são profissionais capacitados, para ficarem responsáveis pelo assessoramento, tornando assim o trabalho de má qualidade, anulando a visibilidade conquistada em períodos de eleições anteriores e podendo comprometer futuras eleições. Nesse sentido, Torquato (2002, p. 81) aponta o crescimento da importância das assessorias: "nos últimos anos, as assessorias de imprensa - chamadas ainda de assessorias de comunicação, designação mais ampla - tiveram um crescimento extraordinário em todo o país".

Nos últimos tempos, com a progressiva utilização das redes sociais online, o cenário da Comunicação Política na Internet exigiu, por parte da assessoria e do ator político, uma atuação diferenciada no que concerne à comunicação realizada para e com os eleitores. A todo momento, os políticos são cobrados por seus representados, também conhecidos por seguidores no campo das redes sociais online, quanto a suas atitudes para determinados acontecimentos ou posicionamentos. Além disso, precisam estar sempre atentos para responderem a seu eleitorado e ao público em geral, que são afetados por suas decisões políticas. Sobre essa atuação no ambiente da web, Ribeiro (2012, p. 2) afirma que:

\footnotetext{
${ }^{5}$ A ideia de redes sociais online, apresentada neste estudo, parte do conceito e da caracterização definidos por Recuero (2011).
}

Comun. \& Inf., Goiânia, GO, v. 20, n. 3, p. 64-83, out./dez. 2017 
Quem optar por atuar na Web deve estar atento à importância de conhecer como funcionam as mídias digitais e as redes digitais, as ferramentas existentes no momento em questão, como as ferramentas tecnológicas contribuem para a criação de novos fluxos comunicacionais que proporcionam a criação de laços, relacionamentos e possibilidades de inúmeras trocas e negociações por aqueles que estão inseridos nessa realidade. É importante também conhecer como funcionam os sistemas de busca, de recomendação e de monitoramento na Web, para poder avaliar sistematicamente se as estratégias de comunicação digital estão obtendo o resultado esperado.

Nesse sentido, inicialmente e de forma exploratória, observamos que o político Marcelo Freixo possui uma assessoria de comunicação especializada para gerenciar o processo comunicacional entre o político e seus eleitores/seguidores no Facebook, pela informação contida em sua fan page $e^{6}$ (Imagem 1), que apresenta o seguinte conteúdo:

Imagem 1 - Texto inicial da Fan Page de Marcelo Freixo.

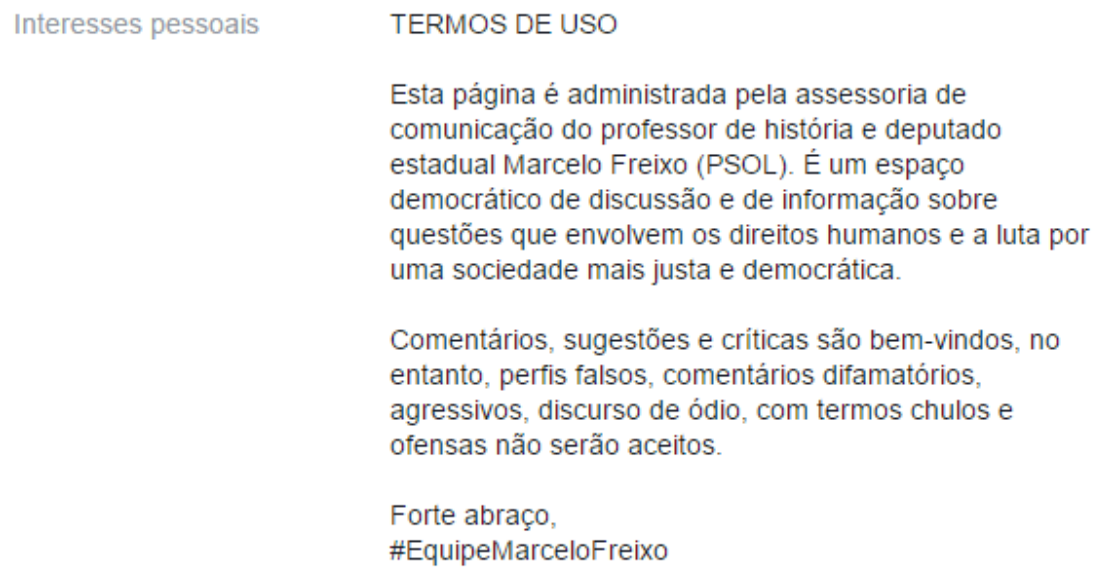

Fonte: Fan page de Marcelo Freixo

A internet emerge na política para aproximar políticos e cidadãos, introduzindo consideráveis mudanças na Comunicação Política. No cenário comunicacional, Thompson (2008) aponta que antes da mídia impressa e de outras mídias serem desenvolvidas, a visibilidade dos líderes políticos dependia, em grande parte, de sua aparição física diante dos cidadãos. Atualmente, a conquista da visibilidade e da legitimação ocorre com a presença dos políticos e de seus representados nas redes sociais online.

\footnotetext{
${ }^{6}$ Atualmente a página possui mais de 450 mil seguidores. Acesso em: 24 jul. 2016.
}

Comun. \& Inf., Goiânia, GO, v. 20, n. 3, p. 64-83, out./dez. 2017 
A partir do case das campanhas eleitorais do presidente estadunidense, Barack Obama, Fraser e Dutta (2008), Serrano (2010) e Câmara e Porto (2009) acenam que os políticos se valem das novas tecnologias para se comunicar abertamente, sem intermediários, com os "cidadãos-eleitores" por meio das redes sociais online, principalmente Facebook e Twitter, classificadas, por parte de políticos e jornalistas, como relevantes fontes de informação e de comunicação.

No entanto, é necessário estar atento, pois assim como as novas tecnologias, em especial a internet, aproximaram o candidato de seu eleitorado, elas oportunizam também uma forma de vigilância ou como Thompson (2008, p. 28) diz: "as novas tecnologias criaram novos meios poderosos de bisbilhotar". Nessa perspectiva, os agentes políticos nos dias atuais possuem maior visibilidade e, ao mesmo tempo, são mais "vigiados" do que em outras épocas. Devido a essa exposição, tudo o que esses políticos dizem ou fazem, ou o que os "outros" declaram sobre eles, podem entrar em conflito com a imagem que desejam construir de si (THOMPSON, 2008). Assim, quando trabalhada de forma inadequada, a visibilidade dada aos líderes políticos pode prejudicá-los.

Em nossa perspectiva de análise, seguimos o pressuposto de Thompson (2008), ao afirmar que a relação entre políticos e seus eleitores efetiva-se gradativamente em forma de quase interação mediada, por meio da qual afetividades podem emergir. Além disso, acena para a necessidade da ajuda de profissionais de relações públicas e de comunicação, de um modo geral, para criar e sustentar uma base que mantenha seu poder e suas políticas, manejando cuidadosamente sua visibilidade e sua apresentação pessoal na arena mediada da política moderna.

A materialidade dessa perspectiva de visibilidade apontada por Thompson é abordada neste estudo a partir do Facebook, rede social online, criada em 2004 por Mark Zuckerberg, Dustin Moskovitz, Eduardo Saverin, Andrew McCollum e Chris Hughes, atingindo, em 2012, a marca de 1 bilhão de usuários ativos (G1, 2016). No Brasil, segundo dados divulgados pela empresa, mais de 99 milhões de pessoas acessam a rede social mensalmente (TECHTUDO, 2016). Isso representa cerca de $45 \%$ da população, segundo o Instituto Brasileiro de Geografia e Estatística (IBGE) (G1, 2015).

A presença da população brasileira na rede social online revela a necessidade dos agentes e dos partidos políticos migrarem para a plataforma e estarem presentes nas novas formas de sociabilidade, já que a Internet é considerada a nova "ágora" que, no mundo helênico, servia como ambiente de reunião das pessoas. Na "ágora" contemporânea, debates 


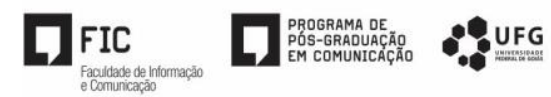

sobre diversas questões surgem de modo inesperado, tomando alcances inimagináveis que podem arruinar a reputação de qualquer agente ou partido político.

A importância do Facebook para a efetividade de campanhas políticas durante e fora dos pleitos eleitorais já é alvo de estudos da própria empresa criadora da rede social. Segundo o diretor de Relações Institucionais do Facebook, Bruno Magrani, após a observação da conjuntura política e das eleições em alguns países, foi possível chegar a uma espécie de manual de sucesso de práticas políticas na rede social (VEJA, 2014). A prevalência no pleito eleitoral dos agentes políticos atuantes na internet está associada a uma postura menos formal, com divulgação dos bastidores da campanha e com uma atuação mais descontraída e acessível.

Em suma, o agente político tem que ser humanizado e, para isso, ele pode e deve utilizar a rede social online para fazer com que o eleitor se sinta próximo a ele, mostrando que não é apenas um candidato político, mas, além disso, cidadão, filho, marido, pai, como todos os demais usuários, e que tem seus direitos e deveres como cidadão. Além disso, a lógica operativa da internet seduz para o consumo de seu conteúdo os jovens, sujeitos mais atuantes nas plataformas digitais, que podem expressar, de maneira mais acentuada, suas vinculações políticas na web, o que outrora era restrito aos ambientes físicos do cotidiano político tradicional (EXAME, 2015).

Do ponto de vista da recepção das postagens de cunho político, Silva (2010) conclui que se trata de uma ação de poucos, mas presenciada por uma multidão silenciosa e atenta, visto que o uso da tecnologia proporciona esse sentimento de pertencimento. Nesse âmbito, o engajamento dos eleitores com a página do Facebook do agente político cresce com a regularidade em que ele atualiza suas publicações. Outro fator importante é transparecer que o político é o responsável pelas publicações de sua página e não uma assessoria, mesmo que na prática ocorra exatamente o contrário.

Ainda segundo as informações de Bruno Magrani, o público não espera que o político esteja 24 horas administrando e atualizando sua página, mas, sempre que possível, é recomendável que faça as chamadas sessões "Face-to-Face", em que ele divulga para os representados que estará "ao vivo" em sua página e disponível para responder a perguntas dos internautas. Em outras palavras, o eleitor quer sempre ter a sensação de que o político está preocupado com seus anseios e que dedica um tempo de sua atenção para administrar a página no Facebook. 
Observando o perfil que o político Marcelo Freixo dispõe no Facebook é possível notar que, em suas publicações, a linguagem é construída de forma a aparentar ser o próprio deputado quem fala com seus seguidores. No entanto, em alguns exemplos, há diferença entre as postagens nas quais o agente político de fato fala com seus seguidores e as que sua assessoria de comunicação gerencia: quando é a assessoria quem realiza a postagem, no fim da mensagem aparece a hashtag \#EquipeMarceloFreixo; quando é o deputado quem realiza a postagem, essa hashtag não se faz presente. Porém, independentemente de quem realiza as postagens na fan page, verificamos um eficiente trabalho para dar visibilidade às ações do político, conforme será abordado, na sequência, a partir da exposição dos dados coletados.

\section{ANÁLISE DA FAN PAGE DE MARCELO FREIXO}

Para alcançar o objetivo proposto neste estudo, a metodologia escolhida é de abordagem quanti-qualitativa (GÜNTHER, 2006; DALFOVO; LANA; SILVEIRA, 2008), com a coleta de dados direcionada pelas pesquisas bibliográfica, documental (GIL, 2008) e exploratória (ISER, 2006). O escrutínio dos dados é inspirado em procedimentos da Análise de Conteúdo (MINAYO, 2007; OLIVEIRA, 2008; BARDIN, 2009), como a "leitura flutuante" e a análise "categorial" das informações.

Os dados (postagens, curtidas, comentários e compartilhamentos) presentes na fan page do deputado Marcelo Freixo foram coletados entre os dias 28 de novembro e 04 de dezembro de 2015, referentes à semana de 01 a 07 de novembro do mesmo ano ${ }^{7}$, resultando em 29 postagens. Para um melhor entendimento sobre como o político utiliza o Facebook, estruturamos os dados em cinco categorias, conforme o tipo de conteúdo presente, detalhando a quantidade de curtidas, compartilhamentos e o número de comentários dos seguidores/usuários e do próprio candidato. Essa análise serve para nos mostrar o tipo de conteúdo que mais engaja o público do deputado e o que lhe possibilita maior visibilidade.

A categorização das informações efetivou-se a partir da análise do conteúdo publicado pelo agente político em sua fan page, mas, além disso, consideramos pesquisas anteriores (CASTRO; FERREIRA, 2014; GONÇALVES; FERREIRA, 2013; MARQUES; SILVA; MATOS, 2012), em que os autores abordam a utilização das redes sociais online, como Facebook e Twitter pelos políticos, categorizando o tipo de conteúdo publicado.

\footnotetext{
${ }^{7}$ Devido a esse intervalo de tempo entre os dias em que as postagens foram realizadas e os dias em que foram coletadas, não podemos dizer se alguma postagem foi apagada ou não se encontra mais na time line da fan page do agente político.
}

Comun. \& Inf., Goiânia, GO, v. 20, n. 3, p. 64-83, out./dez. 2017 
A página oficial de Freixo ${ }^{8}$, que pode ser vista na Imagem 2, apresentava, até o dia 28 de novembro de 2015, um número total de 339.934 curtidas.

Imagem 2 - Capa da fan page de Marcelo Freixo

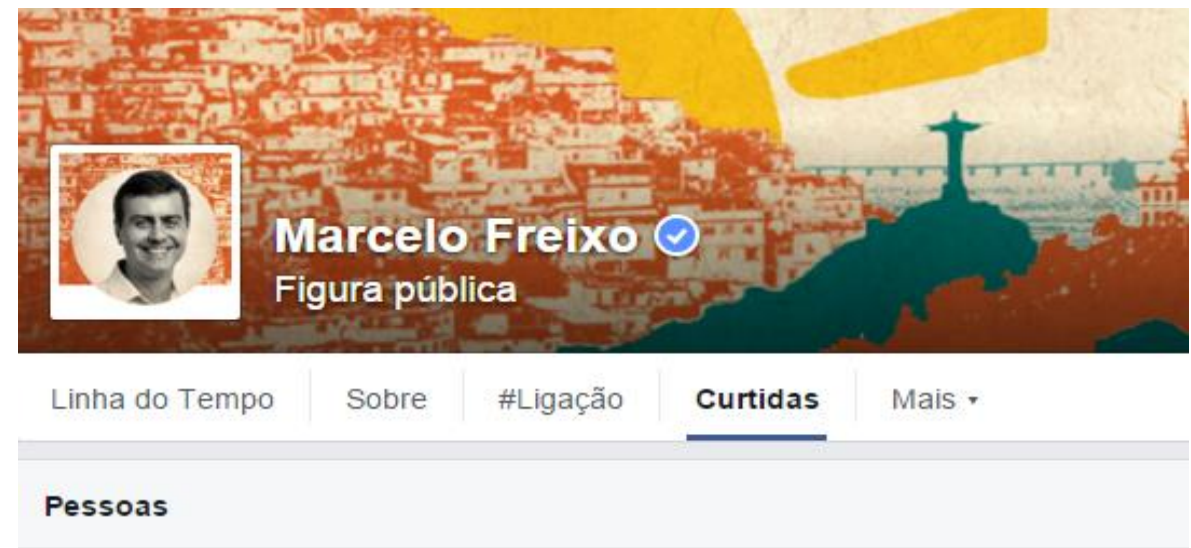

107.722 Pessoas falando sobre isso

339.934 Total de curtidas na Página

$0 \%$ desde a semana passada

Fonte: Fan page de Marcelo Freixo

Na página de Freixo foram coletadas 29 postagens publicadas ao longo de 1 semana (7 dias), totalizando uma média de 4 posts por dia. A Tabela 1 apresenta cinco temáticas, as quais foram divididas por tipo de postagem: promoção de ideias e projetos; ataques e respostas a adversários; divulgação de eventos; mobilização, engajamento e apoio; mensagens alheias à política. Além disso, apresentamos o número de postagens por temática e o que cada uma representa em termos de conteúdo mais disseminado pelo trabalho da assessoria de Freixo.

Tabela 1 - Conteúdo das postagens da fan page de Marcelo Freixo

\begin{tabular}{lcc}
\hline Assunto & No $^{\circ}$ de Postagens & Porcentagem \\
\hline Promoção de ideias e projetos & 7 & $24,13 \%$ \\
\hline Ataques a adversários & 4 & $13,80 \%$
\end{tabular}

\footnotetext{
${ }^{8}$ Disponível em: https://www.facebook.com/MarceloFreixoPsol/?fref=ts. Acesso em: 28 nov. 2015.
}

Comun. \& Inf., Goiânia, GO, v. 20, n. 3, p. 64-83, out./dez. 2017 


\begin{tabular}{lcc}
\hline Divulgação de eventos & 2 & $6,90 \%$ \\
\hline Mobilização, engajamento e apoio & 13 & $44,82 \%$ \\
\hline Mensagens alheias à política & 3 & $10,34 \%$ \\
\hline Total: & 29 & $100 \%$ \\
\hline
\end{tabular}

Fonte: Fan page de Marcelo Freixo

De acordo com a Tabela 1, o tipo de conteúdo mais trabalhado refere-se a "mobilização, engajamento e apoio", representando 44,82\% das publicações, ou seja, quase metade de todo o conteúdo publicado na página de Freixo ao longo da semana, buscando o engajamento de seus seguidores. Logo em seguida, aparecem as postagens sobre "promoção de ideias e projetos", representando $24,13 \%$ das publicações, ou quase um quarto de tudo o que foi publicado ao longo da semana supracitada.

$\mathrm{Na}$ terceira colocação, como conteúdo mais disseminado ao longo do período definido para coleta, estão as postagens de "ataques e respostas a adversários", que foram realizadas em quatro ocasiões diferentes. Por último, apresentam-se as postagens com conteúdos referentes à "divulgação de eventos" (6,90\%) e "mensagens alheias à política" $(10,34 \%)$, que juntas totalizam $17,24 \%$, um número pequeno se comparado aos tipos de publicação.

Diante desses dados, podemos concluir que a assessoria de comunicação do deputado Marcelo Freixo enfatiza três tipos de conteúdo: "mobilização, engajamento e apoio", "promoção de ideias e projetos" e "ataques e respostas a adversários". Juntas, as postagens encontradas nessas temáticas representam $82,75 \%$ de todo conteúdo publicado na fan page observada. Para uma análise mais profunda, sobre o que isso representa, é preciso avaliar a Tabela 2, que mostra a relevância de cada conteúdo em termos de alcance (curtidas, compartilhamentos e comentários) e que, em consequência, transforma-se em visibilidade para o agente político.

Tabela 2- Interações praticadas a partir das postagens na fan page de Marcelo Freixo.

\begin{tabular}{lllll}
\hline & Curtidas & Compartilhamentos & $\begin{array}{l}\text { Comentários de } \\
\text { seguidores }\end{array}$ & $\begin{array}{l}\text { Comentários de } \\
\text { Marcelo Freixo }\end{array}$ \\
\hline $\begin{array}{l}\text { Promoção de } \\
\text { ideias e projetos }\end{array}$ & 23.616 & 9.206 & 1.030 & 1 \\
\hline $\begin{array}{l}\text { Ataques a } \\
\text { adversários }\end{array}$ & 16.255 & 2.643 & 476 & 0
\end{tabular}

Comun. \& Inf., Goiânia, GO, v. 20, n. 3, p. 64-83, out./dez. 2017 


\begin{tabular}{lcccc}
\hline $\begin{array}{l}\text { Divulgação de } \\
\text { eventos }\end{array}$ & 1.048 & 162 & 68 & 0 \\
\hline $\begin{array}{l}\text { Mobilização, } \\
\text { engajamento e } \\
\text { apoio }\end{array}$ & 21.559 & 1.395 & 730 & 5 \\
\hline $\begin{array}{l}\text { Mensagens } \\
\text { alheias à política }\end{array}$ & 12.984 & 387 & 403 & 0 \\
\hline Total: & 75.642 & 13.793 & 2.707 & 6 \\
\hline
\end{tabular}

Fonte: Fan page de Marcelo Freixo

Conforme mostra a Tabela 2, o número total de curtidas nas 29 publicações realizadas ao longo do período observado foi de 75.642 mil. Isso dá um cálculo de aproximadamente 2.608 usuários/seguidores "diretos" atingidos por cada publicação - já que, ao curtir, o usuário demonstra ciência de ter visto, mesmo que superficialmente, o conteúdo publicado. A partir dos dados supracitados, nota-se que o agente político consegue atingir um número muito alto de seguidores e usuários do Facebook, utilizando uma simples ferramenta, que é sua fan page na rede social online, administrada por sua equipe de assessoria de comunicação. Dessa forma, ele consegue atrair uma visibilidade que pode manter o apoio dos eleitores e se converter em votos nas futuras eleições, sem necessariamente ter que se fazer presente fisicamente para o público.

Apesar de ser o conteúdo mais publicado ao longo do período observado, as postagens sobre "mobilização, engajamento e apoio" (21.559) perdem em número de curtidas, compartilhamentos e comentários para as publicações de "promoção de ideias e projetos" (23.616). Essa última possui, apenas em curtidas, quase um terço do total. Contudo, o conteúdo "mobilização, engajamento e apoio" foi o mais disponibilizado por Marcelo Freixo para seus seguidores, visto que é por tal temática que ele busca visibilidade no ambiente virtual.

É importante ressaltar a baixa interação ou taxa de respostas de Marcelo Freixo e de sua equipe ao longo das publicações coletadas. Em apenas seis ocasiões o político, de alguma forma, interagiu com seus seguidores nos comentários das postagens. Esse é um quesito que deveria melhorar na atuação da sua equipe de assessoria. Entretanto, não podemos concluir se essa incipiente interação ocorre por falta de preparo, desleixo ou certo cuidado para evitar polêmicas. Porém, é possível afirmar que essa pouca interação, por meio dos comentários, é um desperdício de oportunidade para o político debater propostas, projetos e ideias com seus eleitores/seguidores. 
Como observado na Tabela 1, os tipos de conteúdo mais presentes nas publicações, ao longo do período observado, diziam respeito à "mobilização, engajamento e apoio", "promoção de ideias e projetos" e "ataques e respostas a adversários". Assim, os dados presentes na Tabela 2 ratificam a capacidade que esses conteúdos possuem de potencializar a visibilidade do deputado Marcelo Freixo. Ao todo, os três tipos de conteúdo atraíram 61.430 curtidas, 13.244 compartilhamentos e 2.236 comentários de eleitores/seguidores.

Isso mostra que o enfoque que a assessoria de comunicação do agente político tem dado às publicações vem conseguido atrair um grande número de pessoas para a plataforma política do deputado. Não podemos inferir que tal estratégia se reverta em votos futuramente, mas indica que Freixo sabe utilizar a comunicação digital para atrair visibilidade, assim como fazem os políticos modernos (THOMPSON, 2008).

Além disso, em uma discussão mais qualitativa dos resultados, observamos algumas constâncias no conteúdo das postagens. Nas relativas à "promoção de ideias e projetos" (Imagem 3), estão as mensagens em que Freixo compartilha e/ou promove seus projetos políticos e as votações e discussões referentes a eles; compartilha links com entrevistas concedidas por ele à imprensa; apresenta seus ideais, seu trabalho e suas reflexões sobre os temas que defende e demais questões inerentes ao cotidiano da sociedade e sobre as quais ele acaba emitindo uma opinião.

Imagem 3 - Exemplo de postagem sobre a temática "promoção de ideias e projetos"

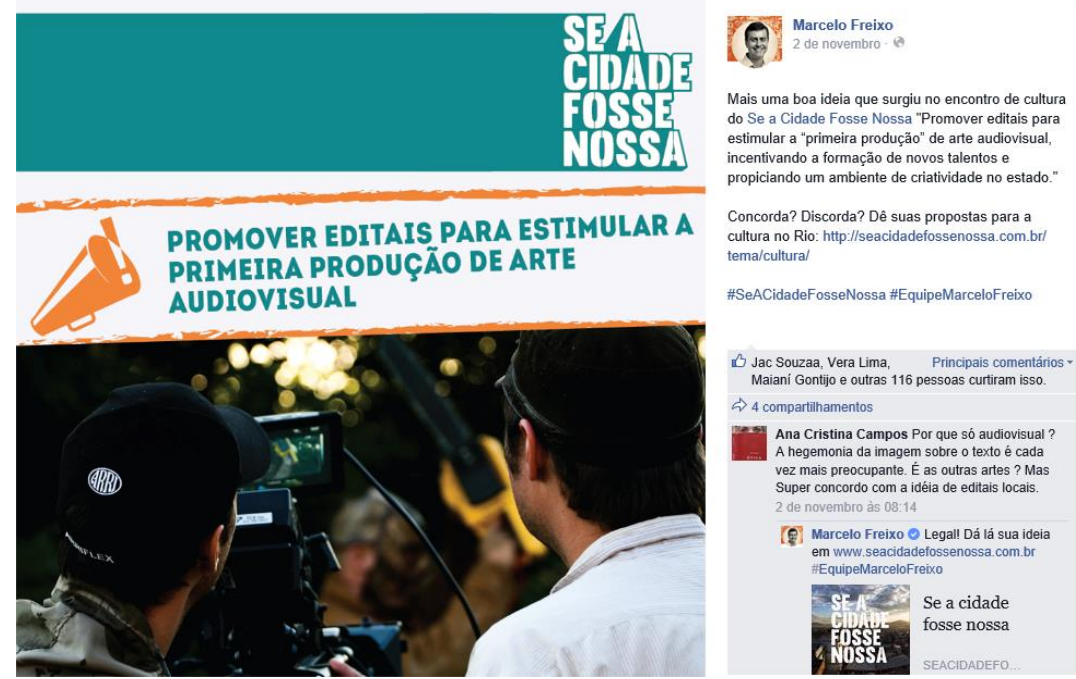

Fonte: Fan page de Marcelo Freixo 
As mensagens direcionadas a "ataques e respostas a adversários" (Imagem 4) são aquelas em que Freixo se preocupa em contestar políticos que compartilham ideais, propõem projetos de lei ou dão declarações que vão contra as crenças defendidas por ele. Nessas publicações de caráter crítico aos adversários, o político compartilha links com matérias, vídeos e publicações, de outros usuários ou páginas, que transmitam algo de cunho negativo sobre outros políticos ou partidos opositores, deixando clara a sua posição. Em outras palavras, objetiva dar visibilidade negativa aos adversários, sem fazer diferenciação no confronto entre o ambiente político regional ou nacional.

Imagem 4 - Exemplo de postagem sobre a temática "ataques e resposta a adversários"

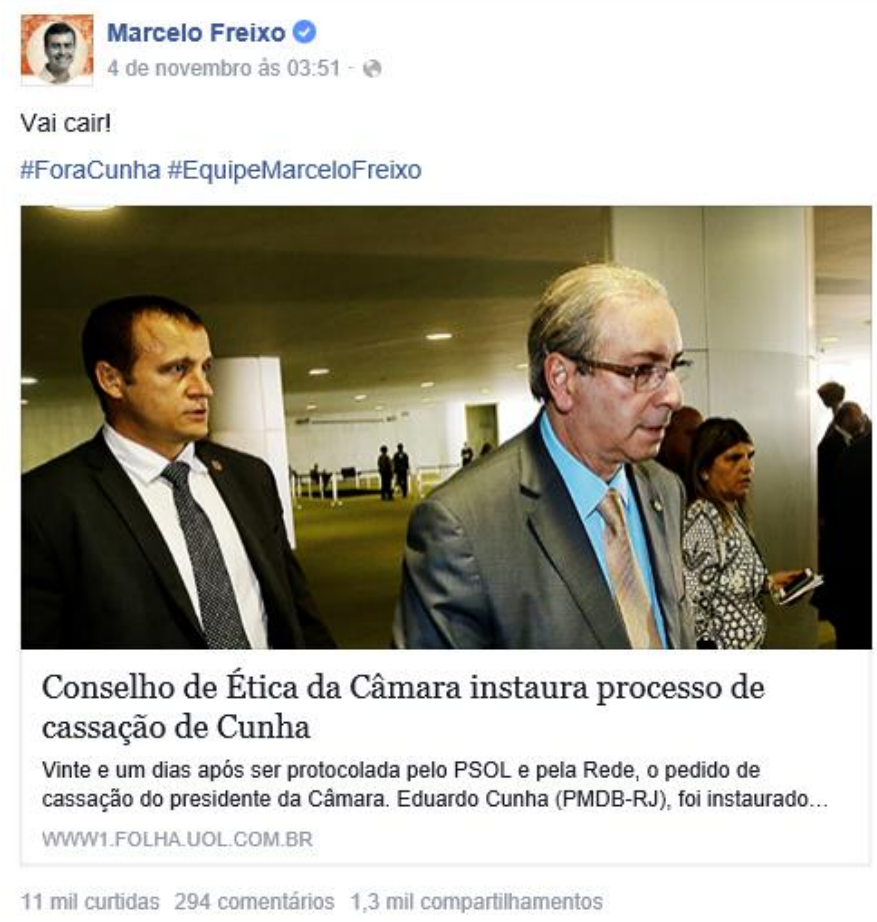

Fonte: Fan page de Marcelo Freixo

As publicações direcionadas à "divulgação de eventos" (Imagem 5) são aquelas em que Freixo convida seus seguidores para participar de rodas de conversas, encontros com representantes do partido ou algum tipo de acontecimento cultural que apoia. Apesar de fazer o convite, ele não necessariamente afirma que estará presente na programação, apenas utiliza sua credibilidade, perante seus seguidores, para legitimar o evento. 
Imagem 5 - Exemplo de postagem sobre a temática "divulgação de eventos"

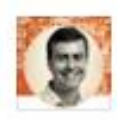

Marcelo Freixo $\odot$ compartilhou o evento de Babilônia Black.

2 de novembro às $14: 26$ - a

Dia 7 vai rolar a 5a edição do Babilônia Black! Cheguem mais:

https://www.facebook.com/events/605508209590429/

\#EquipeMarceloFreixo

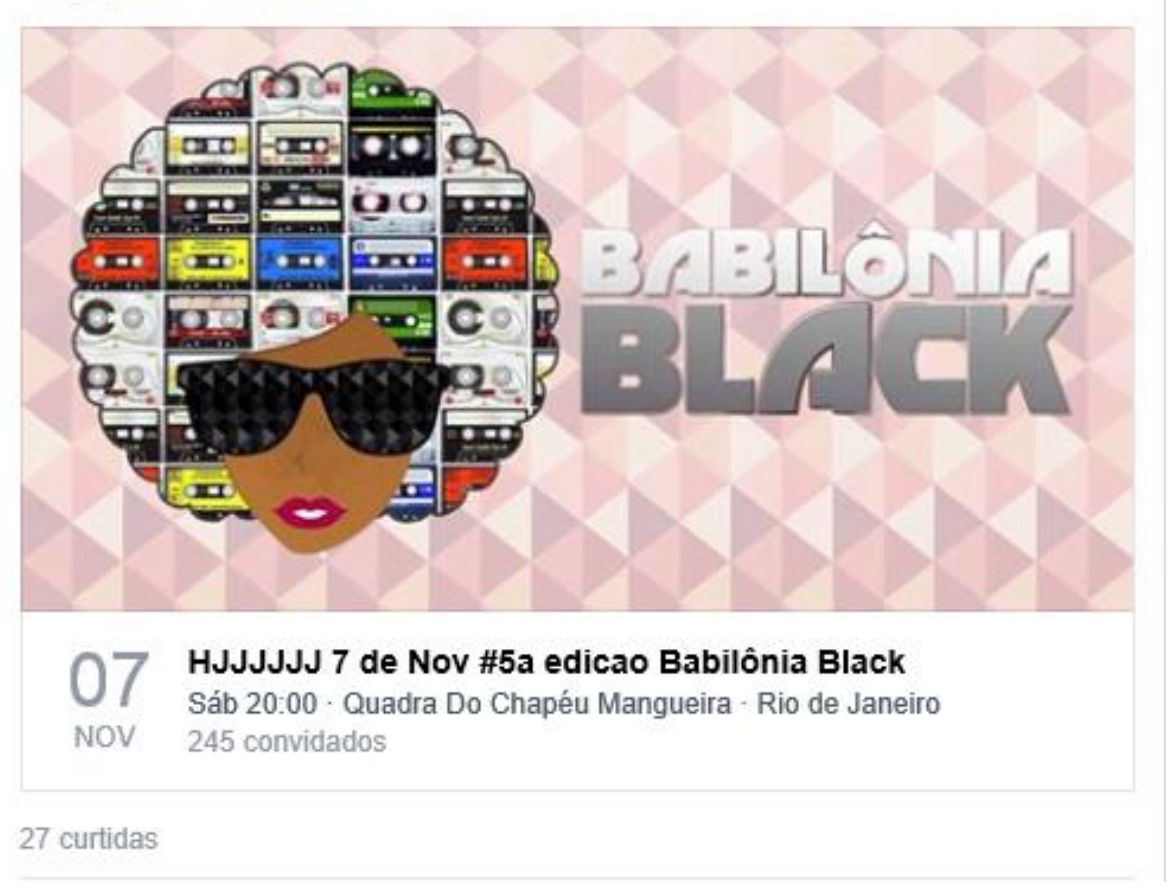

Fonte: Fan page de Marcelo Freixo

Os posts classificados como "mobilização, engajamento e apoio" (Imagem 6) são aqueles em que Freixo informa às pessoas sobre determinado assunto e realça a importância do apoio dos eleitores/seguidores em prol de alguma causa ou expressa solidariedade às vítimas de atos dos quais ele repudia. Por meio de tais conteúdos, o deputado tenta mobilizar 
seus seguidores a participarem de audiências públicas, a darem suas opiniões a projetos e a defenderem bandeiras. Com essas postagens, Freixo tenta engajar seus seguidores a se envolverem ou a apoiarem algum assunto em pauta, vinculado à sua plataforma política e que agregue valor à sua imagem enquanto agente político.

Imagem 6 - Exemplo de postagem sobre a temática "mobilização, engajamento e apoio"

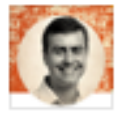

Marcelo Freixo $\odot$

1 de novembro às 17:16 - Editado

Toda solidariedade à Taís Araújo. Lamentável, como disse a sensacional atriz, termos gente tão covarde, pequena e pobre de espírito no país. A indignação move a luta. Todo nosso apoio à tua. Racismo não passará.

4,1 mil curtidas 33 comentários 48 compartilhamentos

Fonte: Fan page de Marcelo Freixo

Por último, temos as postagens classificadas como "mensagens alheias à política" (Imagem 7). Esse é o tipo de conteúdo que não se refere à atuação de Freixo como político, mas sim como um cidadão comum que leva uma vida normal como todos os demais. São postagens que humanizam o agente político, mostrando-o com a família, como um bom pai, um bom marido e um bom filho. Além disso, também apresenta o relacionamento de Freixo com os amigos, aproveitando os dias de folga. Enfim, ações que não dizem respeito ao meio político-partidário, mas que, ainda sim, buscam, de modo humanizado, promover a vinculação com os seus seguidores e, consequentemente, dar-lhe visibilidade.

Imagem 7 - Exemplo de postagem sobre a temática "mensagens alheias à política" 


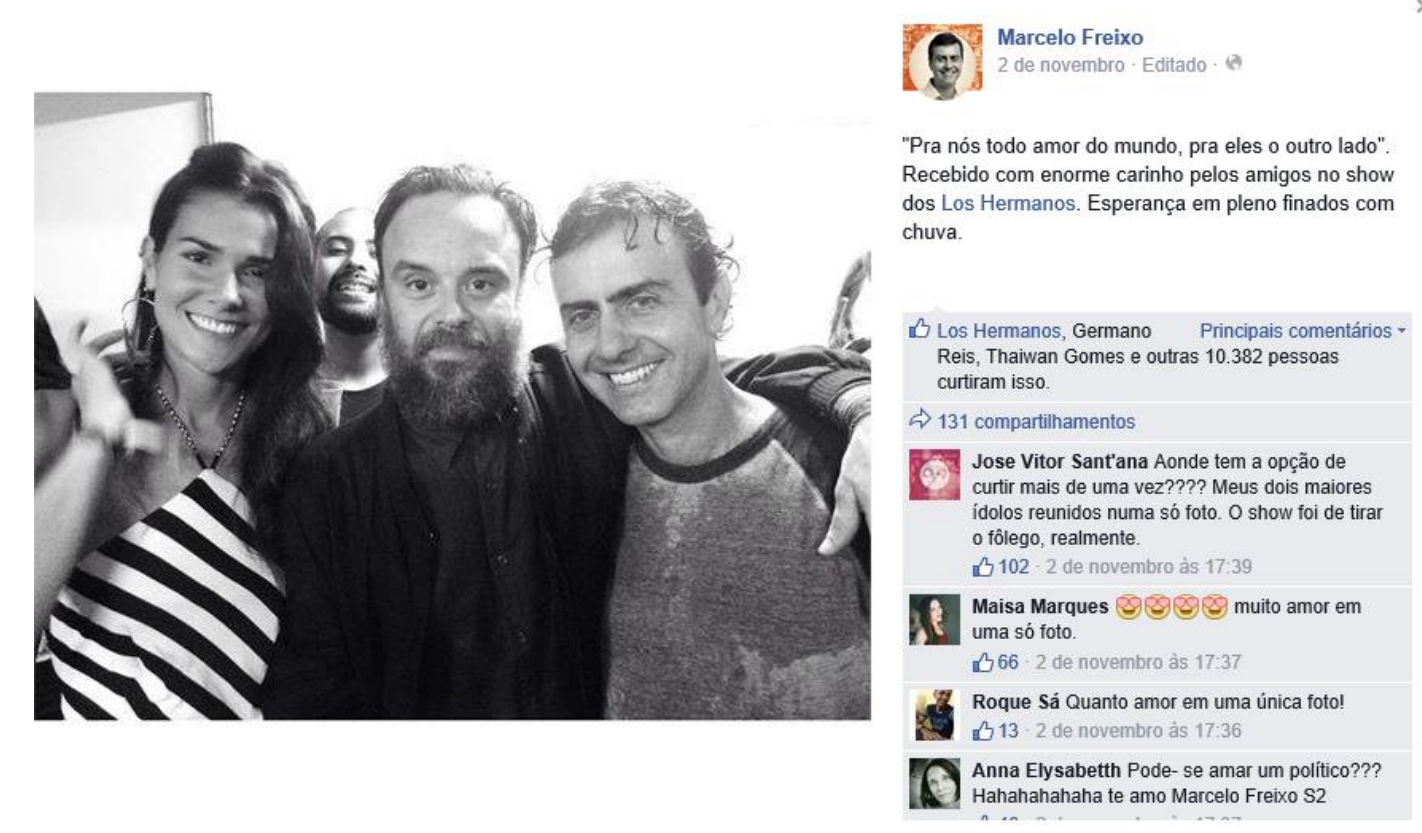

Fonte: Fan page de Marcelo Freixo

Freixo, ao promover sua visibilidade por meio de uma página no Facebook, realiza postagens regulares, apresentando-se como um político preocupado em se comunicar com os eleitores/seguidores. Com o trabalho de uma assessoria de comunicação especializada, faz uso da comunicação digital para se legitimar perante a sociedade, não deixando sua imagem cair no ostracismo. Além disso, com as possibilidades oriundas das plataformas digitais, é possível tornar-se mais conhecido e humanizado até mesmo por pessoas de fora do domicílio eleitoral do Rio de Janeiro.

\section{CONSIDERAÇÕES FINAIS}

Diante de toda a discussão sobre a nova forma de visibilidade (THOMPSON, 2008) apresentada neste estudo, podemos inferir que o debate político, antes restrito a espaços físicos, cresce cada vez mais no ambiente da Internet e de suas redes sociais online, que se materializam na atual conjuntura como ágoras contemporâneas. Nosso objeto empírico - a fan page de Marcelo Freixo - ilustra bem como o Facebook se tornou uma importante plataforma para a realização da Comunicação Política e, consequentemente, uma "vitrine" para os agentes políticos, que dependem de seu bom uso para se projetar e impulsionar a sua visibilidade de forma estratégica e benéfica para si e para suas ideias.

A construção da figura de Marcelo Freixo pela assessoria de comunicação parece atender ao perfil do político moderno: atento às mudanças que ocorrem na sociedade. Ao criar uma página no Facebook para se comunicar com seus eleitores/seguidores, demonstra 
preocupação em promover a interação entre $\mathrm{o}$ agente político e os cidadãos/eleitores/seguidores, fugindo do ultrapassado modo de se aproximar do eleitor apenas em períodos de eleições e/ou com a presença em espaços físicos. Entretanto, em sua fan page, Freixo constantemente busca compartilhar suas ideias e informar seus seguidores sobre os projetos votados ou os que estão a caminho de votação e sobre convites para audiências públicas e rodas de conversas. Assim, Freixo está sempre buscando se aproximar de seus seguidores, mostrando que está disposto a ouvir as opiniões deles.

Considerando os resultados positivos que Freixo obteve nas eleições de 2014 e fazendo uma aproximação com sua visibilidade no Facebook, podemos inferir que ele está munido de uma capacitada equipe de assessoria de comunicação. Nas eleições supracitadas, o deputado estadual conseguiu ser o mais bem votado do Brasil, além de ter tido o melhor custo-benefício de campanha, quando comparado a seus opositores ${ }^{9}$. Vale destacar que suas campanhas contam com financiamento colaborativo, fruto do trabalho constante de diálogo com seus eleitores, por meio das redes sociais online.

Pode-se dizer que a fan page de Freixo consegue projetar e manter sua visibilidade comunicativa na internet, conquistada nas eleições e também fora do período eleitoral. $\mathrm{O}$ deputado carioca é visto como um político transparente, engajado em seus projetos políticos e aberto ao diálogo com a sociedade. Enfim, um político que se preocupa em trazer seus eleitores/seguidores - já que aqui falamos de Facebook - para perto de seu mandato eleitoral.

\section{REFERÊNCIAS}

BARDIN L. Análise de conteúdo. Lisboa: Edições 70, 2009.

CÂMARA, Alexandre; PORTO, Ed. Os seguidores da democracia: um estudo sobre o papel das redes sociais na campanha de Barack Obama. Culturas Midiáticas, v. 2, n. 2, jul./dez. 2009. Disponível em:

<http://www.okara.ufpb.br/ojs/index.php/cm/article/download/11699/6724>. Acesso em: 05 mar. 2016.

CASTRO, Ana Marina de; FERREIRA, Valéria de Melo. Internet e redes sociais, uma nova configuração da democracia midiática: análise dos perfis do Facebook dos três prováveis précandidatos às eleições presidenciais de 2014. In: SEMANA DE PÓS-GRADUAÇÃO EM CIÊNCIA POLÍTICA: REPENSANDO A TRAJETÓRIA DO ESTADO BRASILEIRO, 2. 2014, São Carlos. Anais... São Carlos, 2014.

9 Disponível em: <http://odia.ig.com.br/eleicoes2014/2014-10-10/melhor-custo-beneficio-da-eleicao-e-dopsol.html>. Acesso em: 12 nov. 2015.

Comun. \& Inf., Goiânia, GO, v. 20, n. 3, p. 64-83, out./dez. 2017 
DALFOVO, Michael Samir; LANA, Rogério Adilson; SILVEIRA, Amélia. Métodos quantitativos e qualitativos: um resgate teórico. Revista Interdisciplinar Científica Aplicada, Blumenau, v. 2, n. 4, p. 1-13, 2008. Disponível em: <http://rica.unibes.com.br/index.php/rica/article/viewPDFInterstitial/243/234>. Acesso em: 05 mar. 2016.

DANTAS, Edmundo Brandão. Marketing político: técnicas e gestão no contexto brasileiro. São Paulo: Atlas, 2010.

EXAME. Para nova geração, lugar de política é no Facebook, 2015. Disponível em: $<$ https://exame.abril.com.br/tecnologia/para-nova-geracao-lugar-de-politica-e-no-facebook/>. Acesso em: 23 jun. 2016.

FERRARI, Maria Aparecida. Relações públicas e a opinião pública no composto do marketing político. In: RETZ, Célia. Opinião Pública e Marketing Político. Bauru: FAAC, 2007.

FRASER, Matthew; DUTTA, Soumitra. Barack Obama and the Facebook election. US News, v. 19, 2008. Disponível em: <http://www.usnews.com/articles/opinion/2008/11/19/barackobama-and-the-facebook-election.html>. Acesso em: 05 mar. 2016.

G1. Brasil tem mais de 204 milhões de habitantes, segundo o IBGE, 2015. Disponível em: <http://g1.globo.com/economia/noticia/2015/08/brasil-tem-204-milhoes-de-habitantessegundo-o-ibge.html>. Acesso em: 23 jun. 2016.

G1. Facebook atinge marca de 1 bilhão de usuários todos os dias, 2016. Disponível em: <http://g1.globo.com/tecnologia/noticia/2016/04/facebook-atinge-marca-de1-bilhao-deusuarios-todos-os-dias.html>. Acesso em: 23 jun. 2016.

GIL, Antônio Carlos. Dados e técnicas de pesquisa social. 6. ed. São Paulo: Atlas, 2008.

GOMES, Neusa Demartini. Comunicação Política: olhares convergentes e divergentes.

Revista ECO-Pós, v. 12, n. 3, p. 86-99, set./dez. 2009. Disponível em: $<$ https://revistas.ufrj.br/index.php/eco_pos/article/download/933/873>. Acesso em: 24 fev. 2016.

GONÇALVES, Lorraine; FERREIRA, Adriana Rodrigues. Facebook: a nova ferramenta de campanha eleitoral digital. Panorama, v. 3, n. 1, p. 264-278, jan./dez. 2013. Disponível em: <http://seer.ucg.br/index.php/panorama/article/viewDownloadInterstitial/3441/2012>. Acesso em: 24 fev. 2016. 
GÜNTHER, Hartmut. Pesquisa qualitativa versus pesquisa quantitativa: esta é a questão.

Psicologia: teoria e pesquisa, v. 22, n. 2, p. 201-210, maio/ago. 2006. Disponível em: <http://www.scielo.br/pdf/\%0D/ptp/v22n2/a10v22n2.pdf>. Acesso em: 05 mar. 2016.

ISER, Fabiana. Pesquisa exploratória: a relevância da aproximação empírica para as definições da pesquisa. In: MALDONADO, Alberto Efendy et al. Metodologias da pesquisa em comunicação: olhares, trilhas e processos. Porto Alegre: Sulina, 2006. p. 193-216.

ITUASSU, Arthur; CAPONE, Letícia; PARENTE, Taíse; PECORARO, Caroline. Internet, eleições e democracia: o uso das redes sociais digitais por Marcelo Freixo na campanha de 2012 para a Prefeitura do Rio de Janeiro. Revista Compolítica, v. 2, n. 4, p. 60-86, ago./dez. 2014. Disponível em:

$<$ http://www.compolitica.org/revista/index.php/revista/article/download/152/106>. Acesso em: 24 fev. 2016.

MARQUES, F. P. J. A.; SILVA, Fernando Wisse Oliveira; MATOS, Nina Ribeiro.

Estratégias de Comunicação Política Online: Uma Análise do Perfil de José Serra no Twitter. Contemporânea-Revista de Comunicação e Cultura, v. 9, n. 3, p. 344-369, 2012.

MINAYO, Maria Cecília Souza. O desafio do conhecimento: pesquisa qualitativa em saúde. São Paulo: Hucitec, 2007.

O DIA. Melhor custo-benefício da eleição é do Psol, 2014. Disponível em: $<$ http://odia.ig.com.br/eleicoes2014/2014-10-10/melhor-custo-beneficio-da-eleicao-e-dopsol.html>. Acesso em: 12 nov. 2015.

OLIVEIRA, Denize Cristina de. Análise de conteúdo temático-categorial: uma proposta de sistematização. Rev. enferm. UERJ, Rio de Janeiro, v. 16, n. 4, p. 569-576, out./dez. 2008. Disponível em: <http://www.facenf.uerj.br/v16n4/v16n4a19.pdf>. Acesso em: 02 mar. 2016.

QUEIROZ, Adolpho. Na arena do marketing político: ideologia e propaganda nas campanhas presidenciais brasileiras. São Paulo: Summus Editorial, 2006.

RÁDIO Agência Nacional. Marcelo Freixo foi o deputado estadual mais votado no Brasil, 2014. Disponível em: <http://radioagencianacional.ebc.com.br/politica/audio/201410/marcelo-freixo-foi-o-deputado-estadual-mais-votado-no-brasil>. Acesso em: 23 jun. 2016.

RECUERO, Raquel. Redes sociais na internet. Porto Alegre: Sulina, 2011.

RIBEIRO, Maria Eugênia. O papel do assessor de imprensa em um mundo movido pelas tecnologias digitais. Artigo da Linha de Pesquisa Inovações Tecnológicas na Comunicação Contemporânea. Programa de Pós-Graduação em Comunicação. Universidade Metodista de São Paulo (UMESP). São Bernardo do Campo, 2012. Disponível em: 
<http://www2.metodista.br/unesco/1_Ecom\%202012/GT2/7.O\%20pape1\%20do\%20assessor \%20de\%20imprensa_Maria\%20Eug\%C3\%AAnia.pdf>. Acesso em: 05 mar. 2016.

SERRANO, Estrela. Spin doctoring e profissionalização da comunicação política. In:

CORREIA, João Carlos; FERREIRA, Gil Baptista; ESPÍRITO SANTO, Paula do (Org.)

Conceitos de Comunicação Política, 2010. p. 91-98. Disponível em:

$<$ http://s3.amazonaws.com/academia.edu.documents/30843842/correia-conceitos-

2010.pdf?AWSAccessKeyId=AKIAJ56TQJRTWSMTNPEA\&Expires=1469454398\&Signat ure $=\% 2 \mathrm{~B} 8 \mathrm{DCdgvIqAdPZdpJJaxw1 \% 2Bjkqdc \% 3D \& response-content-}$

disposition=inline\%3B\%20filename\%3DConceitos_de_Comunicacao_Politica.pdf\#page=97>

. Acesso em: 05 mar. 2016.

SILVA, Tarcisio Torres. Experiências políticas em redes sociais: colaboração e ação social num mundo desengajado. Revista Mediação, Belo Horizonte, v. 11, n. 10, jan./jun. 2010. Disponível em: http://www.fumec.br/revistas/mediacao/article/download/302/299>. Acesso em: 05 mar. 2016.

TECHTUDO. Facebook revela dados do Brasil na CPBR9 e WhatsApp 'vira ZapZap', 2016. Disponível em: <http://www.techtudo.com.br/noticias/noticia/2016/01/facebook-reveladados-do-brasil-na-cpbr9-e-whatsapp-vira-zapzap.html>. Acesso em: 23 jun. 2016.

THOMPSON, John B. A nova visibilidade. MATRIZes, v. 1, n. 2, 2008. Disponível em: <http://www.revistas.univerciencia.org/index.php/MATRIZes/article/viewFile/5230/5253>. Acesso em: 05 mar. 2016.

TORQUATO, Francisco Gaudêncio. Tratado da Comunicação: organizacional e política. São Paulo: Pioneira Thomson, 2002.

TREIN, Sérgio Roberto. O letramento político construído pela mídia no Brasil. In: CASTILHO, Alessandra; ROCHA, Daniela; GONDO, Roberto (Org.). Comunicação política na esfera pública: democracia, eleições e cidadania no Brasil. Capivari: Nova Consciência, 2013. v. 1, p. 63-75.

VEJA. Facebook: um novo palanque eleitoral? 2014. Disponível em: <http://veja.abril.com.br/noticia/brasil/facebook-um-novo-palanque-eleitoral/>. Acesso em: 23 jun. 2016. 